\title{
Interviews in Qualitative Research
}

\author{
by King, N., Horrocks, C. and Brooks, J. \\ Publisher: SAGE, London, $2^{\text {nd }} \mathrm{Ed}, 2019$
}

AUTHOR(S) OF THIS REVIEW:

Debbie Reed Msc Dip CIPD PGCHE BA(Hons) Cert Ed CCIPD ORCID: 0000-0002-8593-064X

Head of Centre, Centre for Professional Practice, University of Kent.

\section{Accepted for publication: Nov $3^{\text {rd }} 2019$}

Address correspondence to Debbie Reed, University of Kent D.Reed@kent.ac.uk

Chief Editor: Claire L Parkin ${ }^{\text {PhD }}$. Current affiliation is: Centre for Professional Practice, University of Kent, M3-15 Medway Building, Chatham Maritime, Kent. ME4 4AG. UK.

C.L.Parkin@kent.ac.uk

AJPP@kent.ac.uk

https://journals.kent.ac.uk/index.php/ajpp/index

AJPP (ISSN Number: Online, 2059-3198).

(C)The Author(s). 2019 Open Access This article is distributed under the terms of the Creative Commons Attribution 4.0 International License

(http://creativecommons.org/licenses/by/4.0/), which permits unrestricted use,

distribution, and reproduction in any medium, provided you give appropriate credit to

the original author(s) and the source, provide a link to the Creative Commons license, and indicate if changes were made.

\section{STATEMENT ABOUT THE BOOK'S PURPOSE}

King, Horrocks and Brooks (2019) have provided a clear and helpful methods text, which is a hands-on guide for qualitative researchers. The publication makes the complex processes and intricacies of qualitative interviewing accessible without oversimplifying or losing the nuance and essence of what constitutes sound qualitative interview practice. The latest addition introduces a new contributor, Joanne Brooks. The second edition is longer than the first edition by 101 pages. The new publication brings Ethics in Qualitative Interviewing to the foreground, moving that from Chapter 7 to Chapter 3. There are two new chapters; the first on Visual Methods in Qualitative Interviewing (Chapter 8) and the second, Chapter 12, on Interviews and Discourse Analysis. Prior to the References, the second edition also includes a muchwelcomed Glossary of Terms. The text succeeds in its purpose to offer a practical guide and useful text, equally relevant to qualitative interview researchers no matter their experience. It provides a thorough overview from the philosophical underpinning all the way through to the analysis of interview research data.

Introduction: Interviews in Qualitative Research (2019), written by Nigel King, Christine Horrocks and Joanne Brooks, is an invaluable resource through which researchers might gain the data they seek from the interviews they conduct as part of their research. The text provides detailed guidance from the designing, planning, conducting and analysing of qualitative interviews, and as such, is considered to be a core foundational text. It is a suitable guide for students, novices and experienced researchers seeking to keep up to date with contemporary ideas. Now in its second edition, the text brings together essential updates from when the first edition was published in 2011. It offers templates, check-lists, examples of questions and prompts, interview plans and case studies, access to useful resources that demystify the hitherto unknown for those new to qualitative interviewing, as well as offering quality improvement opportunities or new approaches, for those who are more experienced.

Context: The book provides a means through which to navigate the minefield that can be the delivery of sound qualitative interviewing and the authors write in an accessible style. Esteemed in the field of qualitative research, the authors are long-standing contributors, with well-recognised and valued inclusions in a number of other 
qualitative research texts, particularly but not only, in the disciplines of psychology and business. The authors have a wealth of experience and a real appreciation of the qualitative interviewer's lot; their genuine keenness to encourage like-minded others is evident in the detailed tips that are sprinkled throughout this edition. The book demonstrates comprehensive insight into the day-to-day dilemmas that face qualitative interviewers, including the thorny matters of anonymity and informed consent. The text has thirteen chapters plus a Glossary, Reference List and Index. The earlier chapters focus on the philosophical assumptions underpinning qualitative interviewing, as well as the design of qualitative studies. The new structure of this second edition, brings to the foreground Ethics in Qualitative Interviewing, thus properly recognising and emphasising the importance of ethical decisions and the associated outcomes that are fundamental throughout the entire research process. The middle chapters focus on conducting interviews, taking time to explore the nuances unique to various types of interview, which is particularly useful for students and those seeking new ways to gather data. Remote interviewing in Chapter 7 is particularly useful as an initial port of call for researchers who are considering projects where participants are geographically displaced and hard to reach. This section is also useful for researchers who are forced into situations that necessitate resorting to techniques such as telephone (pp. 116-145) or online interviews to gather interview data, as a consequence of an unforeseen event, that might otherwise undermine the whole project.

Chapter 8 is new and is a welcome addition, focusing on visual methods in qualitative interviewing. The chapter considers the rationale for and utility of visual materials in interviews. It provides useful examples of how visual materials can be used and the considerations and caveats that the researcher should explore when thinking about employing the use of visual materials as part of the research methods strategy. The chapter helpfully distinguishes between the use of pre-existing materials as facilitative stimuli for interviews and material that is created as a result of interviews. Further differentiation is given to visual material generated by the interviewer, distinct from material generated by the interviewee. As with other chapters, this new chapter concludes with helpful signposts for further 'Recommended Reading'.

The later chapters of the book then focus on analysis. Initially, self-analysis in Chapter 9 focuses on reflexivity. Like ethics, the matter of reflexivity is a central thread running from the start to the end of the qualitative research process, so it is a little surprising that it does not appear as an earlier chapter. Nevertheless, there is an introduction to the concept of epoche [pp.230-232] initially defined as a "... process of recognising and setting aside our taken-forgranted ways of seeing the world...". The simple introduction and overview provide stimuli for readers to explore the concept of epoche in more detail, for example, by studying the expansive consideration provided by other methodologists such as Moustakas (1994, pp. 85-90).

The second new chapter, Chapter 12: Interview and Discourse Analysis, focuses on the idea of discourse and considers the theoretical view of social construction and language based on discursive approaches, as a framework for research. The section on discourse and truth provides a helpful definition from du Gray $(1996$, p. 43) of the term 'discourse':

"a group of statements which provide language for talking about a topic and a way of producing a particular kind of knowledge about a topic. Thus, the term refers both to the production of knowledge through language 
and representation and the way that knowledge is institutionalised, shaping social practices and setting new practices into play.".

Chapter 12 also includes an introduction and critical overview of Appreciative Inquiry (Al). The section will be of particular interest to those seeking to understand more about inquiry founded on exploring affirmative assumptions. The authors offer a straightforward five-phased structure for researchers opting to adopt the Al approach for the first time.

In addition to the new approaches to analysis, the publication continues to include the more traditional approaches in Chapter 10, such as thematic analysis. Thematic Analysis is also woven in elsewhere [Chapter 13], related to narrative and qualitative interviews. This makes a clear and simple case for different approaches to narrative inquiry, differentiating between narrative inquiry which might use thematic analysis (focusing on content - what is depicted in the narrative) and inquiry which uses 'narrative analysis' (focusing on structure - how the narrative is told). This is effectively substantiated by the authors' quotation from Riessman $(2005$, p. 3) whose thoughts on shared narratives are that "language is viewed as a source not topic of investigation.".

Reassuringly, this new edition continues to provide a clear overview of a wide selection of verification techniques and credibility indicators that offer researchers a practical way of addressing issues of quality related to a qualitative study. This includes an outline of the distinct criteria for assessing qualitative research created by Lincoln and Guba (1985). Those finding this of particular interest, may also find the comparative table of quantitative and qualitative criteria in O'Leary (2017, pp. 67-68) worthwhile.

Evaluation: Although not published until 2019, this publication does not wrestle issues such as General Data Protection Regulation (GDPR), brought into force in 2018. Neither does the text give any tips on the ethical storage or retention of interview data. This may be a reflection of wishes to appeal to an international audience, rather than a solely UK-based market. In addition, those looking for guidance on interviewing 'elite' or 'specialist' participants would need to seek direction elsewhere (such as Dexter, 2006). Also, just when it was possible to think that philosophical underpinning could not be taken any further, this text provides the reader with more ideas to digest in the form of a new overview of the neo-positivist position (a new inclusion that veteran researchers might particularly appreciate). One minor point that has crept into this edition is the splitting of tables over two pages, which at times presents a challenge to the coherence. An e-book version would be extremely useful for adding to the reading list for academic qualitative modules. Although the free Kindle version, available by downloading the free Kindle app, is a move in the right direction for those with portable devices. Nonetheless, this does not go far enough and no doubt an audio version of the text would be a much-welcomed inclusive enhancement, particularly appreciated by those of us with increasing visual impairments.

Summary: This is an important text for those operating within the field of qualitative interviewing. It has been compiled through detailed engagement with other literature in the area. In some sections it provides an introduction, but the authors have invested time to provide signposts to other work which will allow the reader to explore further. 
Overall, it can be considered a core text for those engaging in interview research methods. The authors present the material in a logical order and the text is crammed full of useful ideas, check-lists and tools to enable researchers and students to conduct sound inquiry using interview methods. It would be a worthwhile addition to the qualitative research section of any library and I for one will be recommending and encouraging my research students to draw on this publication in the future and adding it to the reading list of the modules I convene.

\section{REFERENCES}

Dexter, L. (2006) Elite and specialist interviewing. Colchester: ECPR Press.

Du Gray, P. (1996) Consumption AND Identity at Work. London: Sage.

General Data Protection Regulation (GDPR) (2018) General Data Protection Regulation Guide. Available at: https://www.gov.uk/government/publications/guide-to-the-general-data-protection-regulation (Accessed: 22 Nov 2019).

King, N., Horrocks, C. and Brooks, J. (2019) Interviews in Qualitative Research. $2^{\text {nd }}$ edn. London: Sage.

Lincoln, Y. and Guba, E. (1985) Naturalistic Inquiry. CA: Sage.

Moustakas, C. (1994) Phenomenological Research Methods. London: Sage

O'Leary, Z. (2017) The essential guide to doing your research project. 3rd edn. London: Sage.

Riessman, C. (2005) 'Narrative analysis', In Kelly, N., Horrocks, C., Milnes, K., Roberts, B. and Robinson, D. (eds) (2005) Narrative memory and everyday life. Huddersfield: University of Huddersfield Press, pp?. 